\section{UJMM

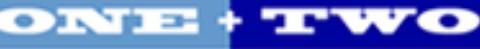

Volume 3 | 2011 Spring

\section{Undergraduate Journal of Mathematical}

Modeling: One + Two

2011

\title{
Adiabatic Flame Temperature for Combustion of Methane
}

Rebeca Pupo

University of South Florida

\author{
Advisors: \\ Brian Curtin, Mathematics and Statistics \\ Scott Campbell, Chemical \& Biomedical Engineering \\ Problem Suggested By: Scott Campbell
}

Follow this and additional works at: https://digitalcommons.usf.edu/ujmm

Part of the Mathematics Commons

UJMM is an open access journal, free to authors and readers, and relies on your support:

Donate Now

\section{Recommended Citation}

Pupo, Rebeca (2011) "Adiabatic Flame Temperature for Combustion of Methane," Undergraduate Journal of Mathematical Modeling: One + Two: Vol. 3: Iss. 2, Article 6.

DOI: http://dx.doi.org/10.5038/2326-3652.3.2.6

Available at: https://digitalcommons.usf.edu/ujmm/vol3/iss2/6 


\title{
Adiabatic Flame Temperature for Combustion of Methane
}

\begin{abstract}
This project calculated the adiabatic flame temperature of a combustion reaction of pure methane and oxygen, assuming that all of the heat liberated by the combustion reaction goes into heating the resulting mixture. Mole fractions of methane to oxygen were computed from 0.05 to 0.95 , in increments of 0.05 , and then an integral was computed was computed with respect to temperature using the moles of product produced or leftover moles of reactants from the starting mole fraction times the specific heat of each respective gas. The highest adiabatic flame temperature evaluated, occurred at a mole fraction of 0.35 .
\end{abstract}

Keywords

Methane Combustion, Specific Heat, Adiabatic Flame Temperature

Creative Commons License

(c) (i) () $\Theta$

This work is licensed under a Creative Commons Attribution-Noncommercial-Share Alike 4.0 License. 


\section{TABLE OF CONTENTS}

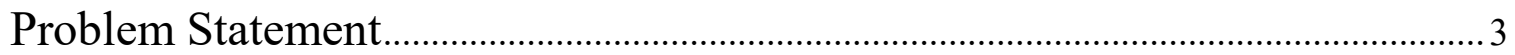

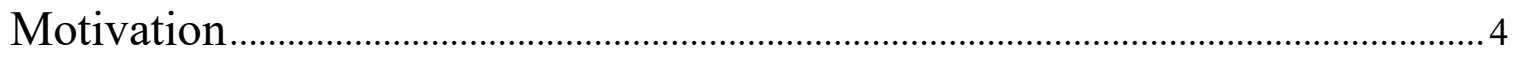

Mathematical Description and Solution Approach ...............................................

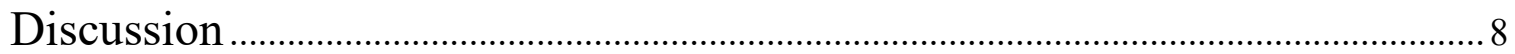

Conclusion and Recommendations....................................................................

Nomenclature

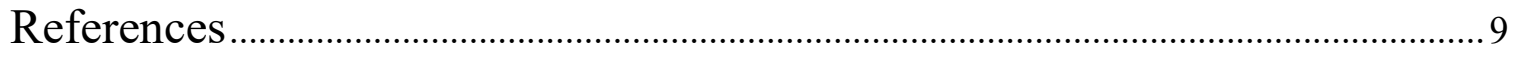

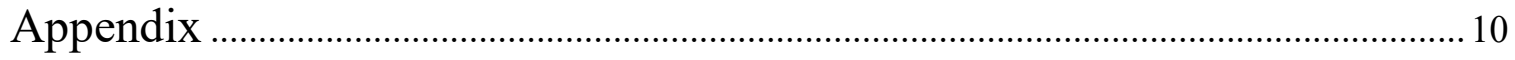




\section{PROBLEM STATEMENT}

Methane $\left(\mathrm{CH}_{4}\right)$ combusts according to:

$$
\mathrm{CH}_{4}+2 \mathrm{O}_{2} \Rightarrow \mathrm{CO}_{2}+2 \mathrm{H}_{2} \mathrm{O}
$$

The goal of this project is to calculate the adiabatic flame temperature $T_{A}$ for this reaction as a function of molar composition (specifically mole fraction of $\mathrm{CH}_{4}$ ) of the feed stream to the reactor. The feed stream consists of only methane and oxygen at $25^{\circ} \mathrm{C}$. The calculation of the adiabatic flame temperature assumes that all of the heat liberated by the combustion reaction goes into heating the resulting mixture. The energy liberated by the reaction is:

$$
\left(n_{C_{4}}^{0}-n_{C H_{4}}\right) \Delta H_{C}
$$

where $n_{\mathrm{CH}_{4}}^{0}$ is the moles of methane fed, $n_{\mathrm{CH}_{4}}$ is the moles of methane that did not combust (if any) and $\Delta H_{C}$ is the heat of combustion of methane at $25^{\circ} \mathrm{C}$ :

$$
\Delta H_{C}=802.3 \mathrm{~kJ} / \mathrm{mole}
$$

of methane reacted.

The energy that goes into heating the product gas is given by:

$$
n_{C H_{4}} \int_{25}^{T} C p_{C H_{4}} d T+n_{O_{2}} \int_{25}^{T} C p_{O_{2}} d T+n_{C O_{2}} \int_{25}^{T} C p_{C O_{2}} d T+n_{H_{2} O} \int_{25}^{T} C p_{H_{2} O} d T
$$

where the $n_{i}$ are the moles of species $i$ that exist after the reaction occurs and the $C p_{i}$ are the heat capacities of each gas participating in the reaction. For the purposes of this project, the heat capacities can be assumed to be linearly dependent on temperature: $C p_{i}=A_{i}+B_{i} T$ where $C p_{i}$ is in $\frac{k J}{m o l}{ }^{\circ} \mathrm{C}$ and $T$ is in ${ }^{\circ} \mathrm{C}$. 
Coefficients $A$ and $B$ for the gases involved here are given in the table below:

\begin{tabular}{|c|c|c|}
\cline { 2 - 3 } \multicolumn{1}{c|}{} & $A$ & $B$ \\
\hline $\mathrm{CH}_{4}$ & 0.034 & $2.50 \mathrm{E}-06$ \\
\hline $\mathrm{O}_{2}$ & 0.030 & $3.00 \mathrm{E}-06$ \\
\hline $\mathrm{CO}_{2}$ & 0.040 & $9.70 \mathrm{E}-06$ \\
\hline $\mathrm{H}_{2} \mathrm{O}$ & 0.033 & $5.50 \mathrm{E}-06$ \\
\hline
\end{tabular}

We will also make a graph of $T_{A}$ versus mole fraction $y$ of methane in the feed stream ranging from $y=0.05$ to $y=0.95$.

\section{MOTIVATION}

The calculation of adiabatic flame temperature is important to people in fields that deal with combustion and explosions. These fields include most material production industries, and also chemical industries. The adiabatic flame temperature is the temperature of the products of a combustion reaction if no heat is lost to the external environment. By being able to calculate the adiabatic flame temperature, these fields can maximize the starting ratio of their reactions in order to get an ideal combustion result.

The objective for this project is to determine the adiabatic flame temperatures for different molar ratios of a mixture of methane and oxygen that combusts and thus get an idea of the ideal conditions for this reaction.

\section{MATHEMATICAL DESCRIPTION AND SOLUTION APPROACH}

The first step in this project is to determine the mole fraction of the reactants, and how many moles of the products are produced in each case. This was calculated using 1 mole of methane for each ratio, using the equation: 


$$
y=\frac{n_{C H_{4}}^{0}}{\left(n_{C H_{4}}^{0}+n_{O_{2}}^{0}\right)}
$$

where $n_{\mathrm{CH}_{4}}^{0}$ is the moles of methane present before the combustion and $n_{\mathrm{O}_{2}}^{0}$ is the moles of oxygen present before the combustion. The initial moles of both methane and oxygen are provided in the chart in Table 2 of the appendix. The moles of methane and oxygen present before combustion can then be used to calculate the limiting reagent on the products after combustion using the following molar ratio of this reaction:

$$
\mathrm{CH}_{4}+2 \mathrm{O}_{2} \Rightarrow \mathrm{CO}_{2}+2 \mathrm{H}_{2} \mathrm{O}
$$

If the amount of methane available will react with less $\mathrm{O}_{2}$ than is available, it is the limiting reagent. The amount of leftover moles of the excess reagent is calculated using the following equation:

$$
n_{\text {excess reagent }}^{0}-\left(n_{\text {limiting reagent }}^{0} \times \frac{\text { molar ratio of excess reagent }}{\text { molar ratio of limiting reagent }}\right)=n_{\text {excess reagent }}
$$

where $n_{x}$ is the moles of the species that exists at the end of the reaction.

The moles of all other products present after combustion should them be calculated using their molar ratios.

$$
n_{\text {limiting reagent }}^{0} \times \frac{\text { molar ratio of product }}{\text { molar ratio of limiting reagent }}=n_{\text {product }}
$$

The results of these calculations are shown in the chart in Table 2 in the appendix. Next, the heat capacities (in $\mathrm{kJ} / \mathrm{mol}$ ) of each gas participating in the reaction must be calculated using the equation:

$$
C p_{i}=A_{i}+B_{i} T
$$


The values for $A_{i}$ and $B_{i}$ for each element are given in Table 1 in the appendix, and the equations for $C p_{i}$ for each element are given by:

$$
\left\{\begin{aligned}
C p_{C_{4}} & =0.034+2.50 \times 10^{-6} T \\
C p_{O_{2}} & =0.030+3.00 \times 10^{-6} T \\
C p_{C O_{2}} & =0.040+9.70 \times 10^{-6} T \\
C p_{H_{2} O} & =0.033+5.50 \times 10^{-6} T
\end{aligned}\right.
$$

In this reaction, it is assumed that all the heat created by the combustion goes into heating the mixture of products. The equation for the energy released by this reaction is:

$$
\left(n_{C H_{4}}^{0}-n_{C H_{4}}\right) \Delta H_{C}
$$

where $H_{C}$, the heat of combustion of methane at $25^{\circ} \mathrm{C}$, is equal to $802.3 \frac{\mathrm{kJ}}{\mathrm{mol}}$ of methane reacted.

The results of this calculation for each mole fraction are shown in the chart in Table 2 in the appendix. This equation is then set equal to the equation that is representative of the energy that goes into heating the product (which, in this case, is all of the energy liberated by the combustion), which is as follows:

$$
n_{C H_{4}} \int_{25}^{T} C p_{C H_{4}} d T+n_{O_{2}} \int_{25}^{T} C p_{O_{2}} d T+n_{C O_{2}} \int_{25}^{T} C p_{C O_{2}} d T+n_{H_{2} O} \int_{25}^{T} C p_{H_{2} O} d T
$$

By substituting in the values for each $n$ and $n^{0}$ and then the equations calculated for each $\mathrm{Cp}_{\mathrm{i}}$, the integral can then be taken to get a polynomial expression. Once a polynomial is obtained, then the quadratic formula can be used to solve for $T_{A}$. The values for $A, B$, and $C$ for each mole fraction are listed in the chart in Table 3 of the appendix. Because the value for the quadratic formula where the square root is added is feasible and the value where the square root is subtracted is not, this value can be discarded and $T_{A}$ assumed to be the value obtained when 
adding the square root. The values calculated when both adding and subtracting the square root are included in the chart in Table 4 of the appendix.

Based on the values obtained when adding the square roots in the quadratic formula, the following graph was produced:

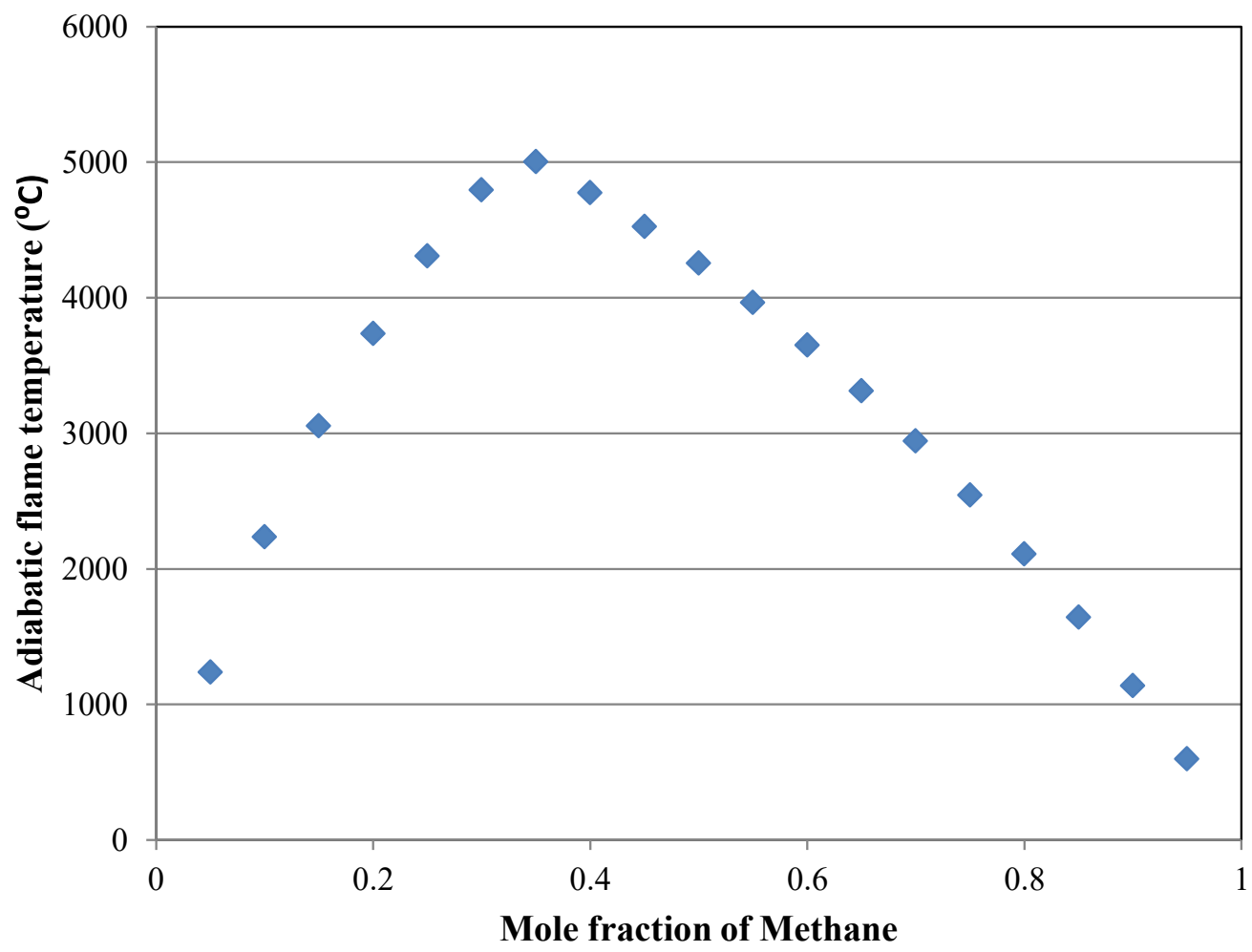

Figure 1: Adiabatic flame temperature as a function of differing ratios of composition of a mixture of methane and oxygen.

It is apparent that the mole fraction evaluated that produces the most heat from combustion would be $y=0.35$. In reality, the mole fraction would be slightly less than 0.35 , because the ideal molar ratio based on the reaction equation would be 1 mole of methane to 2 moles of oxygen. The $y$ value for this ratio would be $0 . \overline{33}$. The values for $y=0.3$ and $y=$ 0.35 , however, are extremely close to this value. 


\section{DISCUSSION}

The result of this project found that the mole fraction $y=0.35$ had the highest resulting adiabatic flame temperature of $5,004^{\circ} \mathrm{C}$. This was as expected, considering the assumed highest adiabatic flame temperature should be at the ideal molar ratio for this reaction, which has a mole fraction of $y=0 . \overline{33}$. Because $0 . \overline{33}$ is closer to 0.35 than 0.30 , it makes sense that 0.35 has the highest adiabatic flame temperature out of all mole fractions analyzed. These results were not surprising, and lend credibility to the use of stoichiometry and balanced reaction equations to determine the ideal ratio of reactants in a reaction.

\section{CONCLUSION AND RECOMMENDATIONS}

Based on the values of $T_{A}$ obtained for each mole fraction from 0.05 and 0.95 , the highest adiabatic flame temperature evaluated occurs at a mole fraction of 0.35 . This is sensible, because according to the balanced reaction equation, the ideal mole fraction that would produce the highest adiabatic flame temperature would be $y=0 . \overline{33}$, which is closer to 0.35 than 0.30 .

To improve on this project, someone doing a similar project in the future might want to focus on the region specifically between $y=0.30$ and $y=0.35$ in order to get a more specific maximum adiabatic flame temperature for this reaction. One issue raised by this project is how the combustion would proceed if methane was combusting with a normal air mixture instead of pure oxygen. This would make for an interesting new study. 
Undergraduate Journal of Mathematical M odeling: One + Two, Vol. 3, Iss. 2 [2011], Art. 6

\section{NOMENCLATURE}

\begin{tabular}{clc}
\hline Symbol & Description & Units \\
\hline $\boldsymbol{y}$ & Mole fraction & (none) \\
$\boldsymbol{n}_{\boldsymbol{x}}^{\mathbf{0}}$ & Initial moles & $\mathrm{mol}$ \\
$\boldsymbol{n}_{\boldsymbol{x}}$ & Final moles & $\mathrm{mol}$ \\
$\boldsymbol{\Delta}_{\boldsymbol{C}}$ & Heat of combustion of & $\mathrm{kJ} / \mathrm{mol}$ \\
$\boldsymbol{C}_{\boldsymbol{i}}$ & Heat capacity & $\mathrm{kJ} /\left(\mathrm{mol} \cdot{ }^{\circ} \mathrm{C}\right)$ \\
$\boldsymbol{A}_{\boldsymbol{i}}$ & Heat capacity coefficient & $\mathrm{kJ} /\left(\mathrm{mol} \cdot{ }^{\circ} \mathrm{C}\right)$ \\
$\boldsymbol{B}_{\boldsymbol{i}}$ & Heat capacity coefficient & $\left.\mathrm{kJ} /\left(\mathrm{mol} \cdot{ }^{\circ} \mathrm{C}\right)^{2}\right)$ \\
$\boldsymbol{T}$ & Temperature & ${ }^{\circ} \mathrm{C}$ \\
$\boldsymbol{T}_{\boldsymbol{A}}$ & Adiabatic flame temperature & ${ }^{\circ} \mathrm{C}$ \\
\hline
\end{tabular}

\section{REFERENCES}

Campbell, Scott. Interview Tampa: University of South Florida, 2011.

Larson, Ron, Robert Hostetler and Bruce Edwards. Calculus. 8th Edition. Boston, MA: Houghton Mifflin Company, 2005. 


\section{APPENDIX}

\begin{tabular}{ccc}
\cline { 2 - 3 } & $\boldsymbol{A}$ & $\boldsymbol{B}\left(\times \mathbf{1 0}^{-\mathbf{6}}\right)$ \\
\hline $\mathrm{CH}_{\mathbf{4}}$ & 0.034 & 2.50 \\
$\boldsymbol{O}_{\mathbf{2}}$ & 0.030 & 3.00 \\
$\mathrm{CO}_{\mathbf{2}}$ & 0.040 & 9.70 \\
$\mathrm{H}_{\mathbf{2}} \boldsymbol{O}$ & 0.033 & 5.50 \\
\hline
\end{tabular}

Table 1: $A_{i}$ and $B_{i}$ for each gas in the reaction.

\begin{tabular}{|c|c|c|c|c|c|c|c|}
\hline$y$ & $\begin{array}{l}n_{C H_{4}}^{0} \\
\text { (mol) }\end{array}$ & $\begin{array}{c}n_{O_{2}}^{0} \\
\text { (mol) }\end{array}$ & $\begin{array}{l}n_{\mathrm{CH}_{4}} \\
\text { (mol) }\end{array}$ & $\begin{array}{c}n_{O_{2}} \\
\text { (mol) }\end{array}$ & $\begin{array}{l}n_{\mathrm{CO}_{2}} \\
\text { (mol) }\end{array}$ & $\begin{array}{l}n_{\mathrm{H}_{2} \mathrm{O}} \\
\text { (mol) }\end{array}$ & $\begin{array}{c}\left(\boldsymbol{n}_{C H_{4}}^{0}-n_{C H_{4}}\right) \Delta H_{C} \\
(\mathrm{~kJ} / \mathrm{mol} \text { methane) }\end{array}$ \\
\hline 0.05 & 1.00 & 19.00 & 0.00 & 17.00 & 1.00 & 2.00 & 802.30 \\
\hline 0.10 & 1.00 & 9.00 & 0.00 & 7.00 & 1.00 & 2.00 & 802.30 \\
\hline 0.15 & 1.00 & 5.67 & 0.00 & 3.67 & 1.00 & 2.00 & 802.30 \\
\hline 0.20 & 1.00 & 4.00 & 0.00 & 2.00 & 1.00 & 2.00 & 802.30 \\
\hline 0.25 & 1.00 & 3.00 & 0.00 & 1.00 & 1.00 & 2.00 & 802.30 \\
\hline 0.30 & 1.00 & 2.33 & 0.00 & 0.33 & 1.00 & 2.00 & 802.30 \\
\hline 0.35 & 1.00 & 1.86 & 0.07 & 0.00 & 0.93 & 1.86 & 744.99 \\
\hline 0.40 & 1.00 & 1.50 & 0.25 & 0.00 & 0.75 & 1.50 & 601.73 \\
\hline 0.45 & 1.00 & 1.22 & 0.39 & 0.00 & 0.61 & 1.22 & 490.29 \\
\hline 0.50 & 1.00 & 1.00 & 0.50 & 0.00 & 0.50 & 1.00 & 401.15 \\
\hline 0.55 & 1.00 & 0.82 & 0.59 & 0.00 & 0.41 & 0.82 & 328.14 \\
\hline 0.60 & 1.00 & 0.67 & 0.67 & 0.00 & 0.33 & 0.67 & 267.41 \\
\hline 0.65 & 1.00 & 0.54 & 0.73 & 0.00 & 0.27 & 0.54 & 215.98 \\
\hline 0.70 & 1.00 & 0.43 & 0.79 & 0.00 & 0.21 & 0.43 & 171.93 \\
\hline 0.75 & 1.00 & 0.33 & 0.83 & 0.00 & 0.17 & 0.33 & 133.74 \\
\hline 0.80 & 1.00 & 0.25 & 0.88 & 0.00 & 0.13 & 0.25 & 100.29 \\
\hline 0.85 & 1.00 & 0.18 & 0.91 & 0.00 & 0.09 & 0.18 & 70.76 \\
\hline 0.90 & 1.00 & 0.11 & 0.94 & 0.00 & 0.06 & 0.11 & 44.61 \\
\hline 0.95 & 1.00 & 0.05 & 0.97 & 0.00 & 0.03 & 0.05 & 21.10 \\
\hline
\end{tabular}

Table 2: For each mole fraction, initial moles of methane and oxygen, resulting moles of methane, oxygen, carbon dioxide, and water, and heat produced by the reaction. 


\begin{tabular}{|c|c|c|c|}
\hline$y$ & $A\left(\times 10^{-6}\right)$ & $B$ & C \\
\hline 0.05 & 35.850 & 0.616 & -817.722 \\
\hline 0.10 & 20.850 & 0.316 & -810.213 \\
\hline 0.15 & 15.851 & 0.216 & -807.710 \\
\hline 0.20 & 13.350 & 0.166 & -806.458 \\
\hline 0.25 & 11.850 & 0.136 & -805.707 \\
\hline 0.30 & 10.850 & 0.116 & -805.207 \\
\hline 0.35 & 9.700 & 0.101 & -747.519 \\
\hline 0.40 & 8.075 & 0.088 & -603.930 \\
\hline 0.45 & 6.810 & 0.078 & -492.240 \\
\hline 0.50 & 5.800 & 0.070 & -402.903 \\
\hline 0.55 & 4.973 & 0.063 & -329.731 \\
\hline 0.60 & 4.283 & 0.058 & -268.860 \\
\hline 0.65 & 3.700 & 0.053 & -217.316 \\
\hline 0.70 & 3.200 & 0.049 & -173.171 \\
\hline 0.75 & 2.767 & 0.046 & -134.895 \\
\hline 0.80 & 2.388 & 0.043 & -101.364 \\
\hline 0.85 & 2.053 & 0.040 & -71.773 \\
\hline 0.90 & 1.755 & 0.038 & -45.559 \\
\hline 0.95 & 1.490 & 0.036 & -22.998 \\
\hline
\end{tabular}

Table 3: The coefficients $A, B$, and $C$ for each mole fraction

\begin{tabular}{|c|c|c|}
\hline$y$ & $+\left({ }^{0} \boldsymbol{C}\right)$ & $-($ Discard $)$ \\
\hline 0.05 & 1238.24 & -18420.9 \\
\hline 0.10 & 2234.52 & -17390.4 \\
\hline 0.15 & 3054.57 & -16682.5 \\
\hline 0.20 & 3735.80 & -16170.3 \\
\hline 0.25 & 4307.57 & -15784.4 \\
\hline 0.30 & 4792.86 & -15484.1 \\
\hline 0.35 & 5003.83 & -15401.4 \\
\hline 0.40 & 4772.67 & -15670.5 \\
\hline 0.45 & 4524.31 & -15976.4 \\
\hline 0.50 & 4255.37 & -16324.3 \\
\hline 0.55 & 3964.38 & -16725.2 \\
\hline 0.60 & 3651.03 & -17192.2 \\
\hline 0.65 & 3310.92 & -17739.5 \\
\hline 0.70 & 2942.74 & -18388.9 \\
\hline 0.75 & 2543.45 & -19169.5 \\
\hline 0.80 & 2110.10 & -20120.6 \\
\hline 0.85 & 1641.45 & -21297.3 \\
\hline 0.90 & 1139.04 & -22784.4 \\
\hline 0.95 & 598.01 & -24696.8 \\
\hline
\end{tabular}

Table 4: Heat produced by the reaction for each mole fraction 